\title{
Percepção dos discentes sobre a formação na universidade através do questionário do estudante do ENADE
}

\author{
Perception of students about formation in the university through the ENADE student questionnaire \\ Percepción de los estudiantes sobre la formación universitaria mediante el cuestionario de
}

estudiantes de ENADE

Recebido: 20/02/2021 | Revisado: 27/02/2021 | Aceito: 04/03/2021 | Publicado: 12/03/2021

\author{
Bruna Alves Teixeira Lima \\ ORCID: https://orcid.org/0000-0001-7175-3526 \\ Universidade Federal da Paraíba, Brasil \\ E-mail: bruna.alves.ifba@hotmail.com \\ Maria Betania Hermenegildo dos Santos \\ ORCID: https://orcid.org/0000-0001-8311-9709 \\ Universidade Federal da Paraíba, Brasil \\ E-mail: mbhds@academico.ufpb.br
}

\begin{abstract}
Resumo
O objetivo dessa pesquisa foi analisar a percepção dos estudantes do curso de Química sobre a sua formação, bem como a sua concepção e a do coordenador do curso sobre o conceito obtido no Exame Nacional de Desempenho dos Estudantes (ENADE). O levantamento dos dados foi realizado por meio do Questionário do Estudante do ENADE 2017 e da aplicação de um questionário aos estudantes e ao coordenador do curso sobre os possíveis fatores que influenciaram no conceito dos cursos. A presente pesquisa pode ser classificada como documental; com uma abordagem quali-quantitativa e de caráter descritivo. Ao analisar as respostas dos discentes quanto a sua percepção sobre o conceito do curso obtido no ENADE 2017 percebemos que esses apontam fatores como: falta de tempo para responder a prova, despreparo, didática ruim por parte dos docentes, falta de interesse em realizar a prova, falta de conhecimento da importância da avaliação, condição socioeconômica e um protesto, gerado em prol de insatisfações vividas pela turma pioneira do curso. O coordenador dos cursos afirma que irá tomar decisões acerca da nota obtida no ENADE. No entanto, não demonstra interesse em utilizar o Questionário do Estudante. Assim, é possível inferir a necessidade de uma reflexão aprofundada sobre as insatisfações dos estudantes e o desenvolvimento de um projeto de divulgação do ENADE. Baseado no apresentado sugerimos a criação de um Comitê de Avaliação que, em conjunto com a coordenação, possa trabalhar no intuito de divulgar e analisar os resultados do ENADE e do Questionário do Estudante.
\end{abstract}

Palavras-chave: Ensino superior; SINAES; Química; Didática.

\begin{abstract}
The objective of this research was to analyze the perception of students of the Chemistry course about their education, in addition to their conception of the course coordinator about the concept obtained in the National Student Performance Exam (ENADE). The data evaluated was carried out through the ENADE 2017 Student Questionnaire and the application of a questionnaire to students and the course coordinator on the possible factors that influenced the concept of the courses. The present research has a quantity-qualitative approach and descriptive. By analyzing the responses of the students to their perception of the concept of the course obtained in the ENADE 2017, we notice that these factors point out to factors such as: not enough time to answer the test, lack of student preparation, poor didactics by the professors, lack of interest in taking the test, lack of knowledge of the importance of evaluation, socioeconomic status and a protest, generated by the unsatisfaction experienced by the pioneer class of the course. The course coordinator states that he will make decisions about the grade obtained in the ENADE, however, he does not show interest in using the Student Questionnaire. It is possible to infer a great necessity for discussions about student dissatisfaction and divulgation of the ENADE. Based on the presented, we suggest the creation of an Evaluation Committee that, together with the coordination, that can work to disseminate and analyze the results of the ENADE and the Student Questionnaire.
\end{abstract}

Keywords: Higher education; SINAES; Chemistry; Didactics.

\section{Resumen}

El objetivo de esta investigación fue analizar la percepción de los estudiantes del curso de Química sobre su formación, además de su concepción del coordinador del curso sobre el concepto obtenido en el Examen Nacional de 
Desempeño del Estudiante (ENADE). Los datos evaluados se llevaron a cabo a través del Cuestionario del Estudiante ENADE 2017 y la aplicación de un cuestionario a los estudiantes y al coordinador del curso sobre los posibles factores que influyeron en el concepto de los cursos. La presente investigación tiene un enfoque cuantitativocualitativo y descriptivo. Al analizar las respuestas de los estudiantes a su percepción del concepto de curso obtenido en la ENADE 2017, notamos que estos factores apuntan a factores como: falta de tiempo para contestar la prueba, falta de preparación de los estudiantes, mala didáctica por los profesores, el desinterés por tomar la prueba, el desconocimiento de la importancia de la evaluación, el nivel socioeconómico y una protesta, generada por la insatisfacción vivida por la clase pionera del curso. El coordinador del curso manifiesta que tomará decisiones sobre la nota obtenida en la ENADE, sin embargo, no muestra interés en utilizar el Cuestionario del Estudiante. Es posible inferir una gran necesidad de discusiones sobre el descontento estudiantil y la divulgación de la ENADE. Con base en lo presentado, sugerimos la creación de un Comité de Evaluación que, junto con la coordinación, pueda trabajar para difundir y analizar los resultados de la ENADE y el Cuestionario del Estudiante.

Palabras clave: Enseñanza superior; SINAES; Química; Cosas didácticas.

\section{Introdução}

O aprendizado dos universitários tem sido influenciado por dois aspectos: a falta de problematização por parte dos professores e a formação profissional que está associada ao acúmulo de teorias, dominando a fragmentação disciplinar. Mesmo tendo grande experiência em pesquisa, os professores universitários estão focados no ensino e não na aprendizagem, na transmissão de conhecimentos e não na construção de saber, postura profissional e da competência técnica, estética, ética e social. Prática esta que estorna uma qualidade de ensino relacionada ao domínio do conteúdo e técnicas, e não focando na transformação das práticas educativas na perspectiva do protagonismo docente e discente (Soares \& Cunha, 2017).

A formação dos universitários deve ir além da grade curricular do curso. No entanto, é possível notar que a pedagogia no ensino superior não tem sido utilizada de maneira que os discentes construam seu conhecimento através da sua realidade e do seu histórico na instituição (Torres \& Almeida, 2013).

De acordo com Almeida \& Pimenta (2014) as práticas docentes do ensino superior em sala de aula devem superar o tradicionalismo, sendo primordial que seja feita uma reflexão não apenas acerca da formação dos professores da educação básica, mas principalmente dos docentes atuantes no ensino superior, no qual muitas vezes o ensino é feito apenas como uma transmissão de conteúdo para seguir a ementa sugerida e a problematização dos conteúdos é deixada de lado.

Seja no ensino médio ou no superior, ensinar Química não tem sido fácil, visto que, para um ensino eficaz, é necessário considerar a relação interpessoal, habilidades e competências. Não somente conhecer o conteúdo a ser ensinado, mas utilizar didática na sua transmissão. Este processo requer uma relação das habilidades e competências, na qual o importante não é só conhecer o conteúdo a ser ministrado, mas a maneira como será ensinado, levando em consideração o contexto em que a interpretação da natureza é um dos objetos dessa ciência, entendendo que a Química abrange vários campos do conhecimento, como psicologia, pedagogia, sociologia e filosofia (Miranda, Rezende, \& Lisbôa, 2015).

As inquietações a respeito da qualidade de ensino são essenciais e as avaliações como o Exame Nacional de Desempenho de Estudantes (ENADE) podem ajudar a identificar as dificuldades existentes nas redes de ensino e melhorá-las. Visto que, segundo a Portaria Normativa no 40 de 12 de dezembro de 2007, artigo 33-D (Brasil, 2011):

O Exame Nacional de Desempenho de Estudantes (ENADE), que integra o Sistema Nacional de Avaliação da Educação Superior (SINAES), tem como objetivo aferir o desempenho dos estudantes em relação aos conteúdos programáticos previstos nas diretrizes curriculares do respectivo curso de graduação, e as habilidades e competências em sua formação.

Merlo (2018, p. 87) acrescenta que a avaliação realizada pelos alunos acerca da instituição é um recurso que permite compreender problemas existentes: 
Entende-se que a combinação do desempenho dos estudantes com as características apontadas pelo questionário proporciona uma gama de informações fundamentadas que podem servir de parâmetros para novas políticas educacionais e, assim, auxiliar na tomada de decisões visando à melhoria dos cursos e, consequentemente, do desempenho discente

Baseado no exposto, o objetivo dessa pesquisa foi analisar a percepção dos estudantes sobre a sua formação no curso de Química da Universidade Federal da Paraíba no Centro de Ciências Agrárias CCA/UFPB, por meio do Questionário do Estudante do ENADE 2017, bem como a sua concepção e a do coordenador do curso sobre o conceito obtido no ENADE.

\section{Metodologia}

A presente pesquisa pode ser classificada quanto ao seu objeto como pesquisa documental, uma vez que, de acordo com Prodanov e Freitas (2013), a análise documental consiste em utilizar materiais que não receberam tratamento analítico e assim fazê-lo.

Quanto à abordagem, essa pesquisa pode ser considerada como quali-quantitativa, pois envolve métodos quantitativos e qualitativos na análise do tema da pesquisa. Para Knechtel (2014, p. 106), essa abordagem "interpreta as informações quantitativas por meio de símbolos numéricos e os dados qualitativos mediante a observação, a interação participativa e a interpretação do discurso dos sujeitos". De acordo com Pereira, Shitsuka, Parreira e Shitsuka (2018); os estudos quali-quanti são aqueles que os resultados numéricos são complementados por resultados qualitativos. Yin (2015); acrescenta que um complementar o outro de modo a fornecer um melhor entendimento do fenômeno em estudo.

A pesquisa também possui caráter descritivo, visto que a pesquisa descritiva visa delinear as características de determinada população ou fenômeno ou o estabelecimento de relações entre variáveis. Utiliza técnicas padronizadas de coleta de dados como o questionário (Prodanov \& Freitas, 2013).

Os participantes da pesquisa foram 15 discentes da turma pioneira do curso de Química da Universidade Federal da Paraíba, localizado no Centro de Ciências Agrárias, que participaram do ENADE 2017. Dos 15 discentes que fizeram a prova, 4 cursavam o Bacharelado e 11 a Licenciatura, destes um total de 11 responderam ao questionário que foi enviado por e-mail. Como modo de preservar suas identidades e organizar as respostas, estes serão apresentados por letras, exemplo: Discente A, Discente B. Participou também o coordenador do curso.

Os dados foram coletados em duas etapas: inicialmente por meio do Questionário do Estudante do ENADE 2017, cujos resultados foram disponibilizados em relatórios emitidos pelo próprio Instituto. Esse relatório foi elaborado a partir da avaliação do ENADE que aconteceu no dia 26 de novembro de 2017, aos discentes dos cursos de Bacharelado e Licenciatura em Química da CCA/UFPB que tinham expectativa de conclusão do curso até julho de 2018 ou com oitenta por cento ou mais da carga horária mínima do currículo concluída. E as respostas de um questionário online (Questionário do Estudante), cujo objetivo era traçar o perfil dos participantes, integrando informações do seu contexto às suas percepções e vivências; além da sua percepção quanto à sua trajetória no curso e na IES, através de questões objetivas que versaram desde a oferta de infraestrutura até a organização acadêmica do curso, inclusive certos aspectos importantes da formação profissional (INEP, 2016).

A segunda etapa foi constituída por dois questionários: um aplicado aos discentes e outro ao coordenador do curso, os quais foram enviados por e-mail.

\section{Resultados e Discussão}

A partir dos objetivos expostos e baseando-se no referencial teórico e na metodologia utilizada, faz-se a apresentação e discussão dos resultados alcançados neste trabalho, os quais foram organizados em duas categorias: análise dos resultados 
obtidos a partir do Questionário do Estudante do ENADE e as respostas dos discentes ao questionário enviado, assim como as respostas do coordenador do curso.

\subsection{Análise das respostas dos discentes ao Questionário do Estudante do ENADE}

A avaliação educativa deve examinar os significados da formação do indivíduo e dos conhecimentos produzidos, com intuito de avanço da ciência, o desenvolvimento do país por meio da participação ativa dos indivíduos em questões sociais e econômicas (INEP, 2016).

Como o objetivo da pesquisa era avaliar a percepção dos discentes quanto à formação acadêmica na universidade, optou-se por examinar as questões do Questionário do Estudante do ENADE que se relacionavam com a opinião dos discentes sobre a organização didático-pedagógica do curso e sua contribuição para sua formação acadêmica, profissional e pessoal.

Segundo Merlo (2018), a avaliação de caráter educativo possibilita obter informações sobre a qualidade acadêmica utilizando o julgamento a respeito de como o sistema de ensino e as instituições de educação superior cumprem suas funções públicas enquanto formadores de cidadãos.

A primeira questão analisada foi sobre o grau de dificuldade da prova de formação geral, $25 \%, 50 \%$ e $25 \%$ dos discentes do curso de Bacharelado em Química do CCA/UFPB opinaram com as alternativas fácil, médio e difícil, respectivamente. Já no curso de Licenciatura dessa instituição, 9\% disseram que a prova estava fácil, 61\% médio, 9\% difícil e $18 \%$ muito difícil. Estes dados estão expressos no Gráfico 1.

Gráfico 1 - Percentual de respostas dos discentes quando questionados: Qual o nível de dificuldade da prova de Formação Geral?

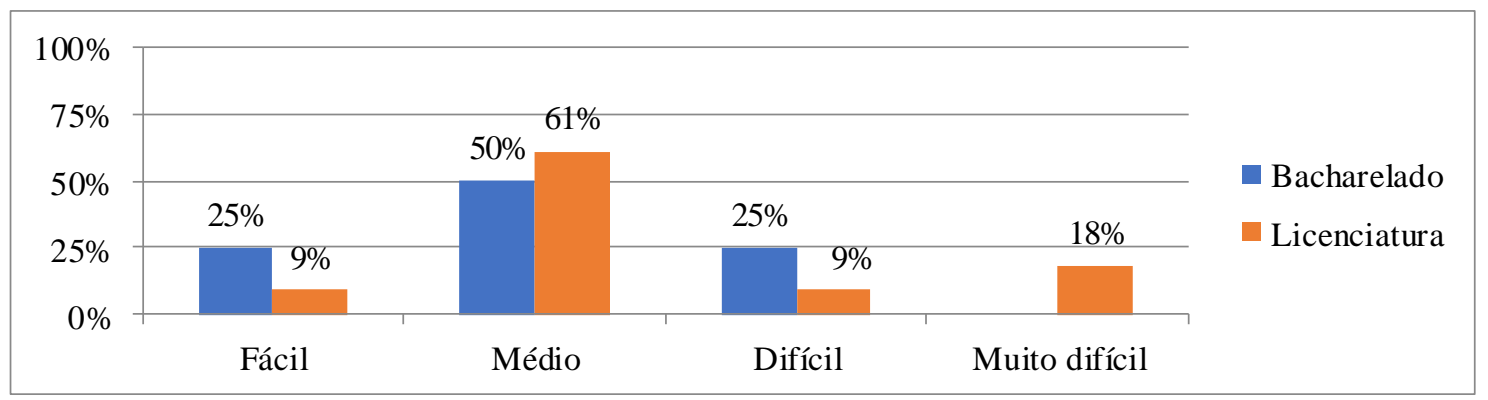

Fonte: Autores (Dados do INEP/DAES 2018).

No âmbito nacional a prova de formação geral foi classificada por $20 \%$ dos discentes inscritos e presentes do curso de Bacharelado em Química como "difícil ou muito difícil". A maioria dos discentes que analisaram a prova como sendo difícil se concentra na região Norte, com 33\%, enquanto a de menor incidência foi no Nordeste, com 19\%. Já dos inscritos e presentes do curso de Licenciatura em Química 27\% afirmaram que a prova foi "difícil ou muito difícil" e $63 \%$ dos discentes as consideram com o grau de dificuldade médio. Dos discentes de Licenciatura em Química que disseram que a prova era muito difícil a maioria está localizada na região Norte, representando 34\%. A região Sudeste foi a que teve menor incidência de discentes que classificaram a prova como muito difícil, com 24\% (INEP, 2018).

Ao serem questionados sobre o grau de dificuldade da prova de conhecimentos específicos $50 \%$ dos discentes do curso de Bacharelado em Química do CCA/UFPB escolheram a opção médio e 50\% difícil. Para 36\%, 18\% e 46\% dos discentes da Licenciatura em Química do CCA/UFPB o nível foi médio, difícil e muito difícil, respectivamente. Esses resultados encontram-se expostos no Gráfico 2. 
Gráfico 2 - Percentual de respostas dos discentes quando questionados: Qual nível de dificuldade da Prova Específica?

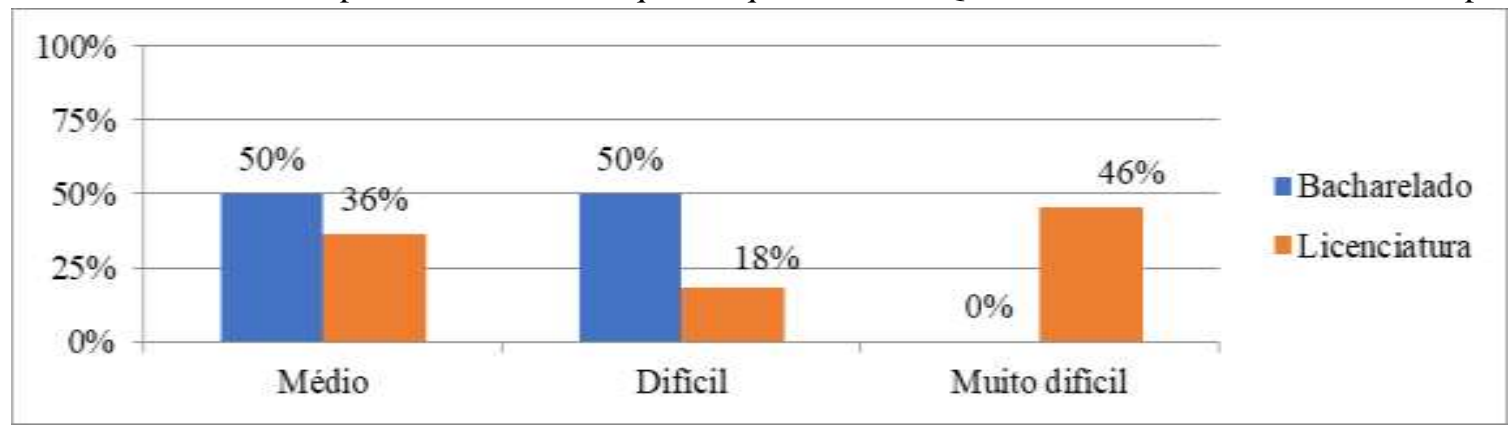

Fonte: Autores (Dados do INEP/DAES 2018).

Ao analisar em nível nacional a prova de conhecimentos específicos $42 \%$ dos discentes do Bacharelado marcaram a opção médio e 48\% difícil. Dos discentes do curso de Licenciatura em Química 55\% classificaram-na como "Difícil ou Muito difícil" e 43\% consideraram com grau de dificuldade "Médio". Averiguando os dados regionais da estatística obtida pelo INEP, a maior incidência da opção "Difícil ou muito difícil” foi na região Centro-Oeste com $61 \%$ e as duas menores proporções nas regiões Sudeste (52\%) e Sul (51\%) (INEP, 2018).

O Gráfico 3 traz a opinião dos discentes quando questionados sobre a possível dificuldade em responder a prova, 50\% dos discentes do Bacharelado responderam "Desconhecimento do conteúdo" e para os outros a dificuldade estaria em "Forma diferente de abordagem do conteúdo". Entre os licenciandos em Química 46\% disseram desconhecer o conteúdo, 36\% assinalaram a alternativa "Forma diferente de abordagem do conteúdo" e 18\% "Falta de motivação para fazer a prova”. O nível de dificuldade e as possíveis causas leva a hipotetizar que os discentes não tinham o preparo necessário, mesmo sendo concluintes, visto que em sua minoria demonstraram desinteresse em realizar a prova como causa da dificuldade.

Gráfico 3 - Percentual de respostas dos discentes quando questionados: Qual as causas da dificuldade durante a prova?

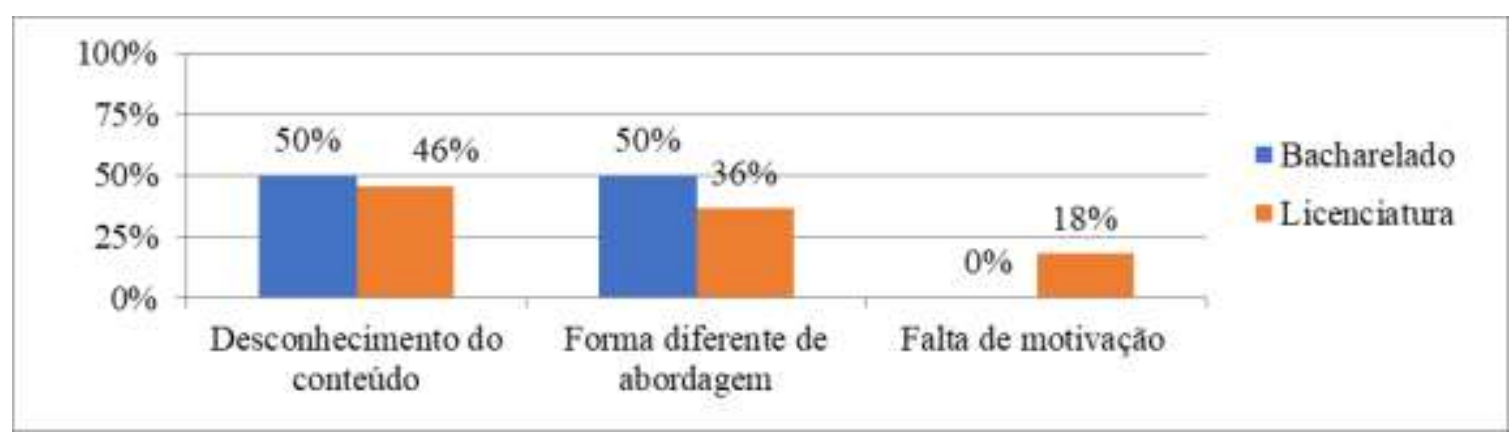

Fonte: Autores (Dados do INEP/DAES 2018).

Em estudo feito por Fonseca \& Santos (2015) 19\% dos estudantes participantes apontaram o desconhecimento do conteúdo como dificuldade em responder a prova. Cerca de $44 \%$ do total indicaram que a "forma diferente de abordagem dos conteúdos" foi o principal complicador na realização da prova. Os autores sugerem que uma possível dificuldade dos alunos pode estar relacionada à falta de interligação do conhecimento da área com os temas gerais da realidade brasileira e mundial, exigência que consta no programa do ENADE.

No Gráfico 4 é possível analisar as respostas dos estudantes acerca da questão "As disciplinas cursadas contribuíram para sua formação integral, como cidadão e profissional”. 
Gráfico 4 - Percentual de respostas dos discentes quando questionados: As disciplinas cursadas contribuíram para sua formação integral, como cidadão e profissional?

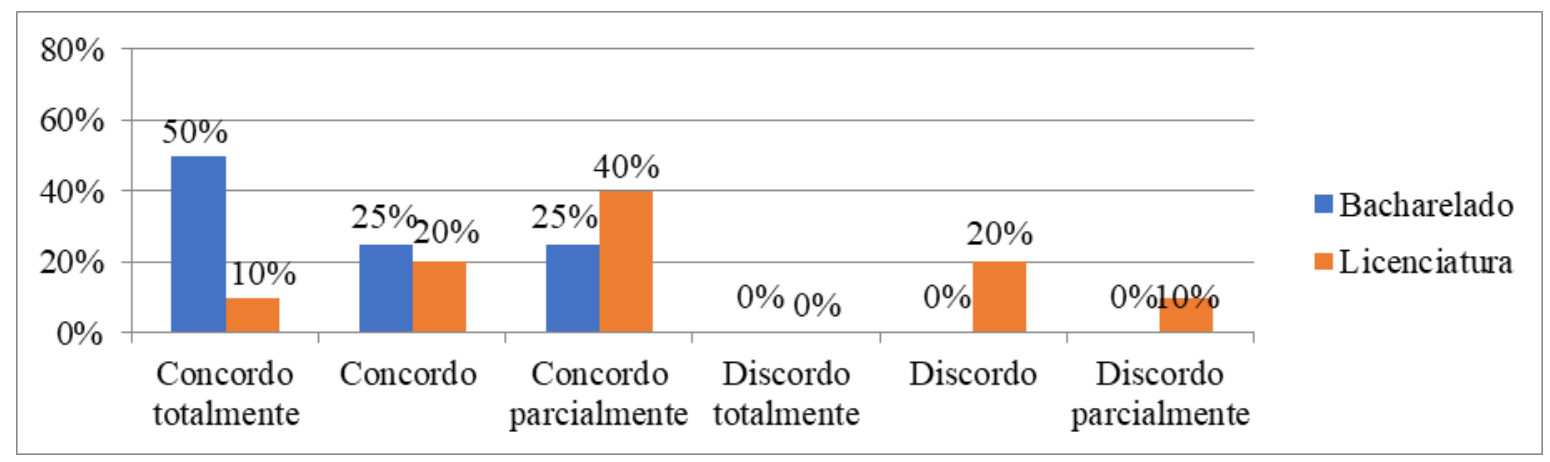

Fonte: Autores (Dados do INEP/DAES 2018).

Os resultados obtidos (Gráfico 4) demonstraram que a metade dos discentes do curso do Bacharelado concorda totalmente que as disciplinas do curso contribuíram para sua formação integral, como cidadão e profissional, já entre os discentes da Licenciatura em Química apenas 10\% concordaram totalmente, 20\% concordaram, 40\% concordaram parcialmente e $30 \%$ discordaram. É possível inferir que os discentes da Licenciatura possuem maior insatisfação. Isso pode ser causado por conta das disciplinas cada vez mais voltadas para o lado científico e que raramente conseguem relacionar a Química com o ensino da disciplina. Ou seja, são formados professores cientistas distantes da realidade da profissão.

No Gráfico 5 é perceptível que os alunos do Bacharelado concordam ou concordam totalmente que o curso contribuiu para o desenvolvimento da sua consciência ética para o exercício profissional, já os resultados obtidos para a Licenciatura foram menores, $54 \%$ concordaram, $9 \%$ concordaram parcialmente e $9 \%$ concordaram totalmente, esses resultados demonstram o contentamento quanto a essa questão.

O ensino com fins éticos forma alunos menos individualistas e constrói um conhecimento comprometido com a humanização e cooperação, focado nas interações sociais, com o objetivo de uma sociedade justa, fraterna e solidária. Para Merlo (2018), o desafio começa com a inserção de disciplinas nos currículos dos cursos, em todos os níveis de ensino, para que a reflexão ética faça parte de todo o processo de formação intelectual e, dessa maneira, contribua com a verdadeira cidadania.

Gráfico 5 - Percentual de respostas dos discentes quando questionados: O curso contribuiu para o desenvolvimento da sua consciência ética para o exercício profissional?

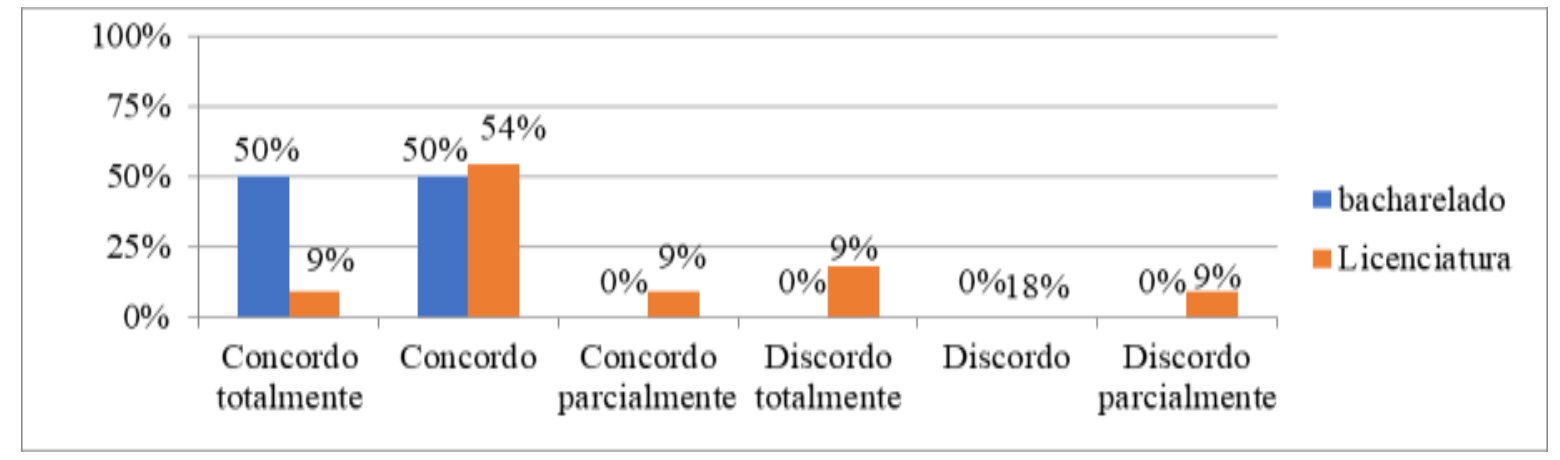

Fonte: Autores (Dados do INEP/DAES 2018).

O Gráfico 6 traz o posicionamento dos discentes quanto ao curso oferecer articulação do conhecimento teórico ao prático, esses são dados importantes sobre a formação tanto do bacharel em Química quanto do licenciado, visto que são profissões onde a prática está diretamente atrelada a teoria estudada. 
Gráfico 6 - Percentual de respostas dos discentes quando questionados: O curso favoreceu a articulação do conhecimento teórico com atividades práticas?

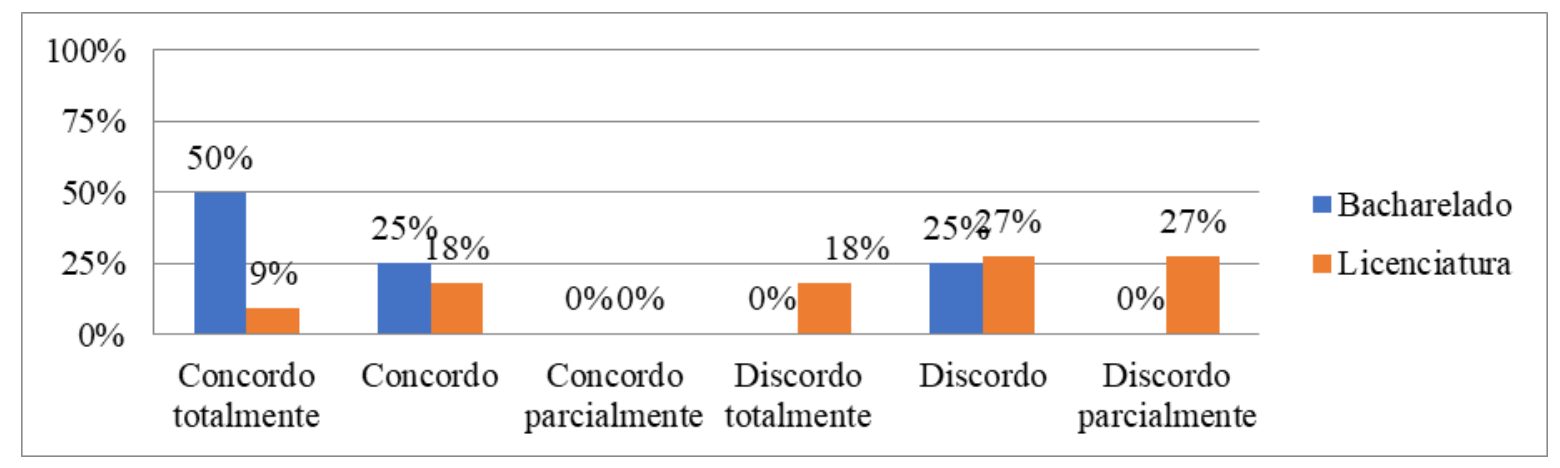

Fonte: Autores (Dados do INEP/DAES 2018).

Baseado no exposto no Gráfico 6 é possível perceber que 75\% dos bacharéis concordam que o curso favorece a articulação entre a prática e a teoria. Porém a maioria dos licenciandos discordam. O curso de Licenciatura em Química da CCA/UFPB possui apenas a disciplina de Metodologia do Ensino de Química, que relaciona a ciência com o ensino. É necessário rever no currículo a oportunidade de mais disciplinas que acrescentem à formação do professor em Química. O posicionamento dos discentes quanto ao curso oferecer articulação do conhecimento teórico ao prático, são dados importantes sobre a formação tanto do bacharel em Química quanto do licenciado, visto que são profissões onde a prática está diretamente atrelada a teoria estudada.

Em análise semelhante Merlo (2018) obteve percentuais baixos de satisfação dos discentes, principalmente no curso de Física. Para a autora esse curso poderia estar fragmentando o ensino dos conteúdos, impossibilitando conexão entre a formação geral do curso e a formação pedagógica. Dessa maneira, os futuros professores não conseguirão transmitir o conteúdo científico adquirido durante o curso numa linguagem acessível a seus alunos. Essa falta de articulação dificulta a elaboração de aulas que sejam claras e coerentes com a realidade da sala de aula. Isso prejudica, em especial, os licenciados de cursos como o de Física, que possuem conteúdos mais abstratos.

De acordo com o Gráfico 7 a maioria dos discentes do Bacharelado concordam que os professores possuem domínio do conteúdo, sendo que $50 \%$ concordam totalmente e $25 \%$ concordam. Dos licenciando $18 \%$ concordam totalmente, $9 \%$ concordam e 36\% concordam parcialmente. O que demonstra existir insatisfação no que diz respeito às aulas. Fonseca e Santos (2015), ao pesquisarem sobre esse tema, obtiveram um melhor resultado, uma vez que $91 \%$ dos discentes disseram que os professores possuem domínio do conteúdo.

Segundo Ramalho (2006); Brzezinski (2002) apenas o domínio do conteúdo não é suficiente para ensinar, é preciso outros conhecimentos, como o pedagógico. De acordo com Pimenta \& Anastasiou (2002), nos processos de formação de professores, é preciso considerar a importância dos saberes das áreas de conhecimento, visto que ninguém ensina o que não sabe, e dos conteúdos pedagógicos, pois ensinar possui diferentes e diversas direções de sentido na formação do humano. No entanto, a realidade é que se prepara o docente para ser pesquisador e não professor, uma vez que não existe uma formação própria para docência na universidade. 
Gráfico 7 - Percentual de respostas dos discentes quando questionados: Os professores demonstram domínio dos conteúdos abordados nas disciplinas?

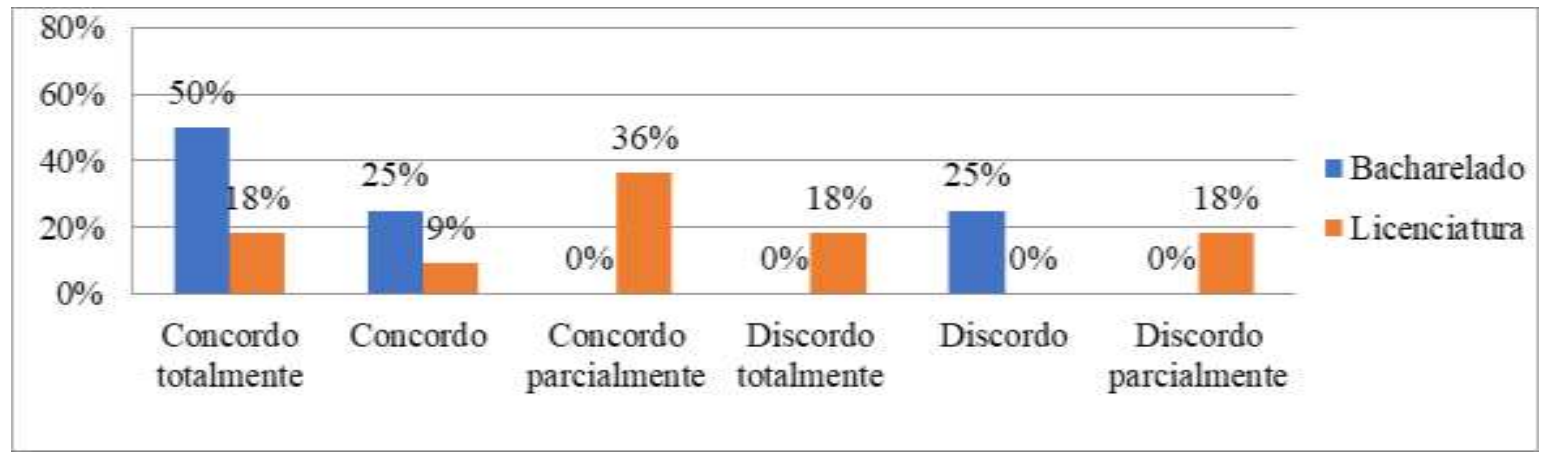

Fonte: Autores (Dados do INEP/DAES 2018).

O Gráfico 8 aponta que $75 \%$ dos alunos do Bacharelado concordam que o curso apresenta monitores e/ou tutores que auxiliem nas disciplinas, já na Licenciatura esse percentual foi um pouco menor (60\%). O curso de Química do CCA/UFPB é um dos que disponibiliza o maior número de bolsistas em monitorias e tutorias no campus. Este último foi implantado pela Universidade Federal da Paraíba (UFPB) a partir das Resoluções nº49/2014/CONSEPE e 16/2015/CONSEPE e tem por objetivo melhorar o ensino, diminuir o alto índice de reprovação, evasão e retenção na instituição.

Gráfico 8 - Percentual de respostas dos discentes quando questionados: Qual o curso disponibilizou monitores ou tutores para auxiliar os estudantes?

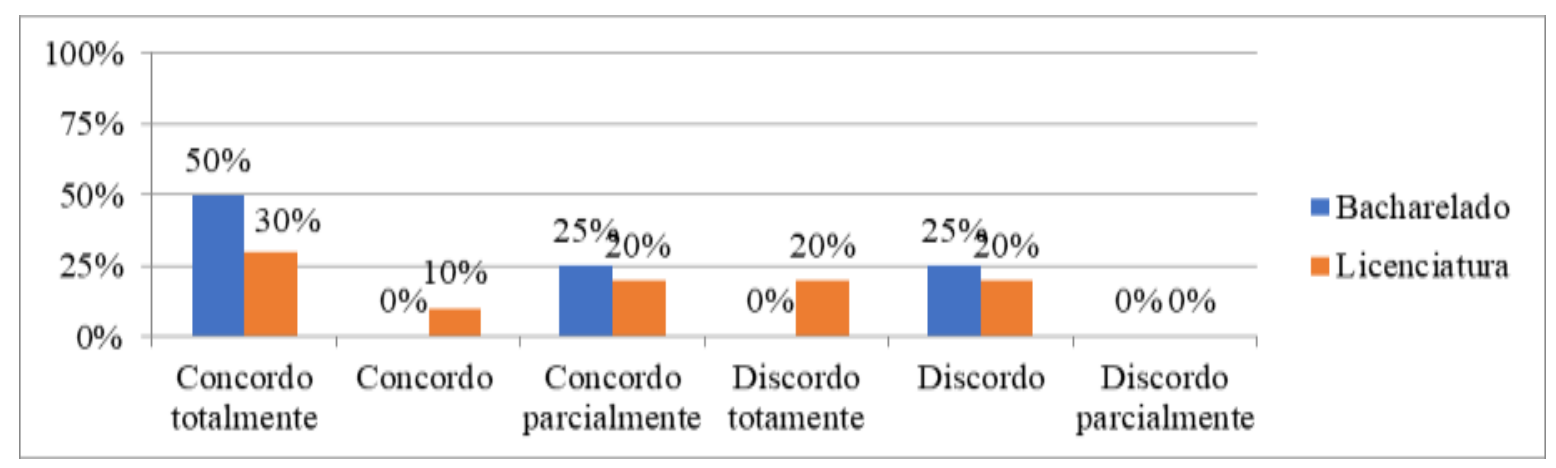

Fonte: Autores (Dados do INEP/DAES 2018).

O Gráfico 9 indica a satisfação dos discentes em relação a adequação dos equipamentos e materiais disponíveis para as aulas práticas e a quantidade de discentes. Entre os discentes do Bacharelado $25 \%$ concordam totalmente e 50\% concordam parcialmente. Já os licenciandos $27 \%$ concordam totalmente, $18 \%$ concordam e $18 \%$ concordam parcialmente. Ou seja, a maioria dos discentes está satisfeita com a estrutura das aulas práticas.

De acordo com Mello e Sousa (2015) a infraestrutura não apresenta relação com o desempenho no ENADE, uma vez que o seu levantamento apontou que entre os conceitos 3, 4 e 5, 67\% eram representados por instituições públicas e $26 \%$ eram instituições privadas neste intervalo. Dessa maneira, foi possível concluir no estudo feito que apesar das instituições privadas oferecerem uma melhor infraestrutura para os seus discentes, este fator é irrelevante para o desempenho dos alunos na prova do ENADE e no conceito geral divulgado por ele. 
Gráfico 9 - Percentual de respostas dos discentes quando questionados: Os equipamentos e materiais disponíveis para as aulas práticas foram adequados para a quantidade de estudantes?

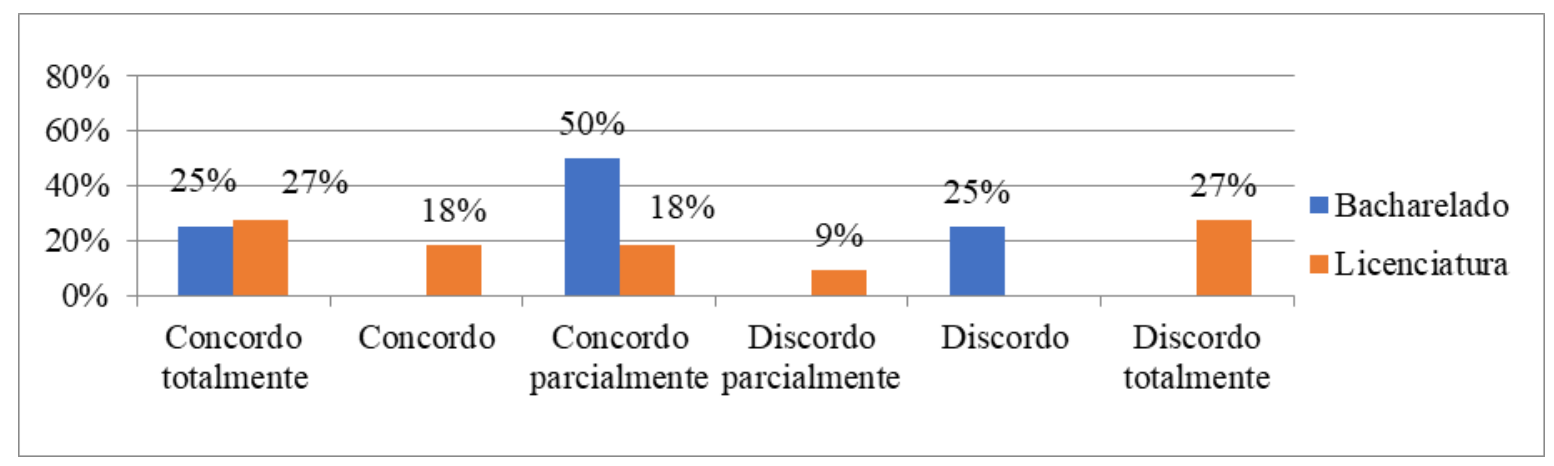

Fonte: Autores (Dados do INEP/DAES 2018).

\subsection{Análise das Respostas dos Discentes e do Coordenador do Curso de Química}

A partir do Questionário do Estudante do ENADE é possível revisar o projeto político pedagógico, conhecer o nível de aprendizado dos discentes e melhorar quesitos importantes. Nesse sentido, é importante conhecer a partir da percepção dos discentes e do coordenador do curso sobre a formação no CCA/UFPB e analisar fatores que influenciem no conceito da avaliação.

Os alunos do curso de Química CCA/UFPB participantes do ENADE 2017 responderam a seguinte questão "Na sua percepção quais fatores influenciaram nessa nota do ENADE 2017?”. Os argumentos desses estudantes serão apresentados ao decorrer da discussão.

Segundo o discente A, a falta de tempo ao responder a prova foi um dos fatores que o prejudicou durante a avaliação:

Na minha opinião o que influenciou foi o pouco tempo que os alunos tiveram para fazer a prova, acredito também que a prova foi um pouco extensa e um dos motivos mais importante é que os alunos demonstraram que precisa acontecer algumas mudanças na maneira que estão formando os educandos, precisa-se buscar mais reflexão, contextualização dos conteúdos para assim, eles não decorem para a prova mas sim aprendam significativamente.

Porém, segundo o relatório do INEP, 50\% dos bacharéis utilizaram entre uma e duas horas para responder a prova, $25 \%$ utilizou entre duas e três horas e $25 \%$ de três a quatro horas. Entre os licenciandos, $36,7 \%$ utilizou entre uma e duas horas de prova, $27,3 \%$ utilizou duas a três horas e 27,3\% entre três a quatro horas. Dessa forma, é possível inferir que há divergência no depoimento, visto que a maioria não permaneceu o tempo disponível para fazer a prova.

Os discentes L e G citam como fatores que influenciaram na nota do ENADE o despreparo para resolvê-lo:

[...]me referencio com relação à algumas disciplinas, que deveriam ser divididas em no mínimo duas disciplinas, por serem muito extensas. Onde poderiam dividir e dar o conteúdo de maneira que os alunos absorvessem mais. Mas alguns professores davam conteúdo de dois semestres em um único semestre, isso com certeza fez com que a o aprendizado fosse menor. [...]

O discente $\mathrm{G}$ acrescenta um momento difícil durante a graduação com a contratação de um professor que, no entanto, apenas preencheu a lacuna, sem dar importância ao conhecimento dos estudantes.

Outros fatores que também correlacionam com o resultado, foi a deficiência dos alunos em algumas áreas específicas, tendo em vista que quem fez a prova fazia parte da turma pioneira do CAMPUS II - UFPB, onde tentaram pagar algumas disciplinas que foram mal apresentadas, sem ter visto conteúdos que deveriam ter sido apresentados e até mesmo sem aulas práticas. Como por exemplo, os alunos matricularam a disciplina de inorgânica que se encontrava sem professor. Faltando pouco tempo para terminar o semestre o professor assumiu a disciplina e os alunos tiveram pouco tempo para ver os assuntos e foram avaliados exclusivamente por uma "prova" que acabou sendo pesquisada e em grupo. 
O discente I discorda quanto ao despreparo e diz que todos tinham visto os conteúdos da prova específica, principalmente nas disciplinas de ensino, lecionadas para a Licenciatura. Como está em sua fala:

[...] Um fato importante é que a maioria das questões relacionadas à química havia sido estudada e sendo assim era possivel as suas resoluções, além disso, TODAS as questões referentes às disciplinas de educação haviam sido discutidas e trabalhadas em suas respectivas disciplinas.

Alguns discentes relataram não saber da importância da prova, demonstrando a falta da cultura da avaliação no curso. Essa afirmação é comprovada com o depoimento do discente B:

Um dos principais fatores pode estar relacionado a falta de interesse de muitos dos participantes que não levaram a sério a resolução da prova. Uma possibilidade para este fato, pode ser a de que muitos não tem o conhecimento dos prejuízos que uma má classificação acarreta para o curso.

O fato de não dar importância à prova e às consequências é diretamente relacionado à falta de conhecimento acerca do ENADE. Em sua pesquisa Oliveira (2014) retratou a necessidade da cultura da avaliação nas Instituições de ensino. Ter a avaliação presente no dia a dia sendo divulgada sem que precise o Estado dar início a isso. Segundo ele, ainda há muito a ser feito em questão à participação dos discentes no ENADE, é necessário a conscientização da comunidade acadêmica acerca da importância da avaliação e da sua contribuição orientadora na constituição do currículo dos cursos. Nesse sentido, é necessário ser repensado sobre a motivação do discente para participação no ENADE (Griboski, 2012).

$\mathrm{O}$ discente $\mathrm{F}$ traz uma opinião parecida com a do discente $\mathrm{B}$, que pode ser acompanhada em seguida:

Um dos fatores cruciais para esse resultado, foi a falta de estímulo dos participantes em realizar a prova, grande maioria dos colegas só foram realizar a prova por motivo de ser obrigatório fazer o exame e só assim conseguir receber o diploma, ao contrário disso, grande maioria consideram o exame como irrelevante e insignificante na avaliação da graduação, pois o resultado pouco irá influenciar na carreira acadêmica, portanto acham desnecessário realizar o exame e com isso não há interesse e nem esforço para obter um bom resultado.

O discente acrescenta dizendo que o exame é desnecessário à carreira acadêmica e esse é um dos fatores recorrentes do desinteresse. Os discentes G, J e D relatam a mesma opinião e justificam ir fazer a prova exclusivamente pela obrigatoriedade. O discente D aponta ainda que esta seria uma falha do MEC. Como pode ser visto a seguir:

Discente G

Um dos principais fatores que influenciaram o resultado do ENADE foi a falta de comprometimento dos alunos com o exame. Alguns fizeram por fazer e outros, que foram a minoria, fizeram o que puderam e o que souberam responder.

Discente J

A falta de motivação por grande parte dos alunos de química foi o principal fator para obtenção desse conceito. Outros fatores como número de estudantes baixo, (Bacharelado 4 pessoas), prova extensa acabou por afetar o desempenho dos alunos e o conceito do curso.

Discente D

[...] Um dos motivos bem notório é a simples obrigatoriedade de fazer a prova do ENADE, não importando a nota que o aluno alcance, na minha opinião isso é uma falha grande do MEC. 
A falta de comprometimento do aluno com o ENADE é relacionada também com o descaso com a própria formação profissional e em relação às disciplinas teóricas. Visto que essa também é uma etapa importante de sua formação (Lehfeld; Caritá; Gabarra, \& Miranda, 2016).

Há uma falha grande na falta de divulgação dos motivos pelos quais existe o ENADE e sua importância. Sabendo disso não seria necessária a obrigatoriedade, e sim os discentes o fariam por dar valor ao exame e reconhecer que ele pode trazer ganhos a sua formação.

Apenas o discente $\mathrm{C}$ relacionou o conceito baixo à renda familiar. Como é possível ver a seguir:

Primeiramente, os alunos dos cursos de Química da UFPB já ingressam na instituição com um baixo potencial acadêmico, constituído em diversos espaços de aprendizagem que já estariam sendo frequentados antes do ingresso na universidade. Além disso, o questionário socioeconômico demonstrou que a maioria desses alunos possuem condições socioeconômicas e culturais desprivilegiadas. Portanto, a associação dessas condições contribui para a consolidação do resultado [...]

De modo geral, a falta de comprometimento dos discentes com seu próprio aprendizado e com a prova do ENADE e o contexto pedagógico que por vezes favorece esse desinteresse em relação à formação teórica contribuíram para o desempenho insatisfatório dos discentes no ENADE (Lehfeld, Caritá, Gabarra, \& Miranda, 2016).

$\mathrm{O}$ discente $\mathrm{D}$ relacionou a nota com o fato de não ser a primeira escolha de curso da maioria dos estudantes:

Um grande percentual da turma estava no curso, mas demonstravam não ser o curso de sua preferência, ou seja, fazer só por fazer, com certeza uns 90 por cento da turma foram nessa situação.

No decorrer de sua fala o discente D complementa que muitos discentes frequentavam o curso apenas para manter suas respectivas bolsas de estudo. Relata ainda que a formação dos professores não é suficiente no âmbito da didática. A formação do docente universitário tem sido marcada por constantes mudanças de saberes. Muito resultado de práticas configuradas em uma cultura profissional baseada em conhecimentos teóricos tradicionais que necessitam ser atualizadas. São mudanças e exigências que acontecem muito rápido e, na maioria das vezes, o docente precisa redimensionar suas atividades para compreender e acompanhar as transformações do cotidiano (Bleichvel, 2017). A fala do discente também relata a falta de didática por parte do corpo docente, apresentado a seguir:

Falta de preparo da maioria dos professores para repassar o conhecimento aos alunos, exigindo que os alunos adquiram conhecimento apenas com o auxílio de livros didáticos, não se preocupando com os conhecimentos prévios e também não proporcionando uma boa relação entre professor e aluno.

Pela lei $\mathbf{n}^{0}$ 5.539, de 27 de novembro de 1968, o docente universitário deverá possuir competências que contemplem o ensino e a pesquisa (Brasil, 1968):

Art $5^{\circ}$ Haverá apenas uma carreira docente, obedecendo ao princípio de integração entre ensino e pesquisa.

Parágrafo único. Caberá aos departamentos, na organização de seus programas, distribuir os trabalhos de ensino e pesquisa, de forma a harmonizar os interesses do departamento e as preocupações científico-culturais dominantes do seu pessoal docente.

O Art. 10 dessa lei salienta a necessidade de um currículo apropriado para contratação:

Parágrafo único. As universidades e os estabelecimentos isolados disciplinarão o concurso referido neste artigo, atribuindo valor preponderante ao curriculum vitae e ao teor científico dos trabalhos dos candidatos interessados.

A Lei de Diretrizes e Bases - LDB/96 traz poucas exigências referente à formação dos docentes. No artigo 52 em seu segundo inciso, no que se trata da formação do quadro de profissionais especifica apenas a titulação necessária (Brasil, 2003): 
II - Um terço do corpo docente, pelo menos, com titulação acadêmica de mestrado ou doutorado.

Entre os discentes participantes quatro confirmam a hipótese de um boicote ao curso em forma de manifesto devido a falhas na administração do curso. Posteriormente a percepção do discente H:

Na minha concepção os fatores que mais influenciaram uma nota tão baixa foram a falta de atitude da coordenação para com os alunos tanto da Licenciatura quanto para os do bacharel e a burocratização de assuntos de interesse dos alunos os quais tinham que se humilhar para resolver problemas que outras coordenações resolvem em um piscar de olhos. Com isso a maioria dos alunos encontrou no ENADE uma forma não de se vingar mais sim de mostrar sua indignação para com a coordenação.

De acordo com o discente $\mathrm{H}$ a insatisfação partia do descaso da coordenação em resolver os problemas. $\mathrm{O}$ discente $\mathrm{A}$ e o I contam logo abaixo sobre o supracitado boicote:

\section{Discente A}

[...]Com relação a não responder as questões do ENADE, uma "turma ". se reuniu e decidiram não responder as questões, pois pensavam que se a nota fosse muito baixa, mudaria alguma coisa nos cursos. Onde existe uma burocracia enorme para resolução de alguns pequenos problemas, enfrentados por parte dos estudantes. Burocracias essas que já haviam sido conversadas com a coordenação, e a mesma não se movimentava[...]

\section{Discente I}

Uma forma utilizada pelos discentes para demonstrar a sua insatisfação com a coordenação e o departamento de química, pois os alunos solicitavam atitudes dos mesmos em relação a problemas enfrentados na graduação e os representantes se mantiveram neutros, ou seja, não se posicionaram a favor dos alunos buscando a resolução dessas dificuldades[...]

$\mathrm{O}$ discente $\mathrm{K}$ justifica o boicote com a retenção sofrida em determinada disciplina, o que gerou uma insatisfação resultando no desinteresse ao responder a avaliação, como está retratado a seguir:

Alguns alunos se sentiram retidos no curso devido a algumas disciplinas de um certo professor, o que acarretou na falta de interesse destes alunos se darem ao menos o trabalho de ler as questões, o que acabou por prejudicar a nota do curso.

Em sua pesquisa Merlo (2018) analisou uma situação semelhante, e acrescenta que em um curso considerado novo, no qual ainda estão traçando os caminhos para consolidarem-se, é esperado que os discentes respondam, de modo geral, que as condições estão insatisfatórias. Seus resultados apontam que quanto ao uso dos dados do Questionário acredita-se que a instituição não esteja dando crédito para essas informações. A autora acresce que, somente uma análise aprofundada, poderá identificar a realidade da instituição. O público-alvo da pesquisa supracitada sugere a implementação de seminários para a discussão dos Questionários do Estudante, e dessa forma poder alcançar melhorias na Instituição.

É considerável que enquanto mecanismo de avaliação do ensino superior os dados do relatório do INEP podem apresentar limitações. No entanto, ainda é um recurso útil para orientar as ações pedagógicas e administrativas da IES e do Curso, visto que constituem importantes referências para o conhecimento da realidade institucional e para a melhoria da qualidade de ensino (INEP, 2018).

Baseado no apresentado foi questionado ao coordenador do curso: Quais as ações pedagógicas e administrativas que a coordenação dos cursos de Química do CCA/UFPB, irão realizar uma vez que o conceito dos cursos foi 1. As respostas foram os seguintes: 
1) Campanha de Valorização da Prova do ENADE com ênfase no reflexo da relação entre a nota do exame e a aceitação dos egressos pelo mercado de profissional

2) Avaliação e Reforma do PPC frente os desafios atuais da profissão, assunto já em discussão no NDE ${ }^{1}$.

3) Avaliação dos(as) discentes com provas dos anos anteriores em diferentes períodos dos cursos de Química do $C C A / U F P B$.

É possível inferir que o coordenador não comenta a possibilidade de avaliar a percepção dos estudantes presentes no Questionário do Estudante. Em sua pesquisa Merlo (2018) identifica que 14\% dos coordenadores entrevistados não tinham sequer noção da quantidade de informações contidas no Questionário do Estudante, como por exemplo, a percepção sobre a qualidade do ensino e condições dos recursos físicos e pedagógicos, e 71,5\% não efetuou alteração no curso utilizando desses dados.

Ao responder a questão, na sua percepção quais fatores influenciaram nessa nota do ENADE 2017?, o coordenador comenta a necessidade de discutir em reunião a situação do conceito do curso ser baixo. Entretanto o coordenador em questão não demonstra em nenhuma de suas falas querer saber a opinião dos discentes sobre o curso. Como assim expressa abaixo.

A viabilidade de técnica e administrativa de tais ações será tema de discussão da próxima reunião do colegiado dos cursos de Química, visando subsidiar uma discussão mais ampla junto a PRG/UFPB com o objetivo de otimizar metas para o máximo rendimento dos discentes neste exame.

Sabendo da opinião dos estudantes é possível adaptar mudanças no curso e diminuir possíveis insatisfações. Merlo (2018) afirma que entre as mudanças possíveis sugeridas pelos coordenadores em sua pesquisa tem-se a alteração no Projeto Político Pedagógico (PPC) do curso com inclusão de novas disciplinas, mudança na carga horária e na bibliografia utilizada nas disciplinas, alteração nas condições de estágio, mudanças na estrutura do curso com o objetivo de interligar a grade pedagógica com a área profissional do discente e a realização de uma pesquisa interna com os alunos no meio do curso, ou seja, muito antes de participarem do ENADE, com o propósito de saber das insatisfações dos alunos a tempo de solucioná-las. A opinião de um dos participantes faz-se cabível também aos docentes, pois não somente a coordenação ou chefia de departamento precisam pensar em melhorias para o curso. Como, por exemplo, a participação em uma Comissão Própria de Avaliação (CPA) ou um Núcleo Docente Estruturante (NDE) de cada curso.

\section{Considerações Finais}

Ao analisar o Questionário do Estudante do ENADE, podemos inferir que: os alunos, tanto do Bacharelado como da Licenciatura, tiveram dificuldade em responder a prova de formação geral. No entanto, essa dificuldade foi maior na de conhecimentos específicos. Quando questionados sobre os motivos da dificuldade durante a prova, a maioria dos alunos citou desconhecer o conteúdo e o modo diferente de abordagem da prova. Os licenciandos demonstraram maior insatisfação quanto ao curso proporcionar a articulação entre a prática e a teoria e domínio do conteúdo pelos professores. Isso permite inferir a defasagem de disciplinas que permitam relacionar a Química com a prática de ensino.

Baseado na análise das respostas do coordenador do curso e dos estudantes foi possível concluir que: O coordenador afirma que irá tomar decisões acerca da nota obtida no ENADE, no entanto não demonstra interesse em utilizar o Questionário do Estudante ou tomar decisões em conjunto com a opinião dos discentes. Os discentes destacaram como principais causas da nota do ENADE falta de tempo para responder a prova, despreparo, didática ruim por parte dos docentes, falta de interesse em realizar a prova, falta de conhecimento da importância da avaliação, condição socioeconômica e um protesto, gerado em prol de insatisfações vividas pela turma pioneira do curso.

${ }^{1}$ NDE- Núcleo Docente Estruturante. 
Baseado no apresentado sugerimos a criação de um Comitê de Avaliação que, em conjunto com a coordenação, possa trabalhar no intuito de divulgar e analisar os resultados do ENADE e do Questionário do Estudante. É possível sugerir também uma avaliação no currículo dos licenciandos para que eles possam ser tanto bons químicos quanto bons professores. Os resultados dessa avaliação podem ser aprofundados em um futuro trabalho.

\section{Referências}

Almeida, M. I., \& Pimenta, S. G. (2014). Pedagogia Universitária - Valorizando o ensino e à docência na universidade. Revista Portuguesa de Educação, $27(1), 7-31$

Bleichvel, R. de C. (2017) O ENADE diante da formação docente universitária e o conhecimento científico. Revista Internacional de Educação Superior, 3(2), $322-335$.

Brasil. (1968). Decreto-Lei $n^{o}$ 5.539, de 27 de novembro de 1968. Dispõe sobre o Estatuto do Magistério Superior. http://www.planalto.gov.br/cciv il_03/LEIS/1950-1969/L5539.htm.

Brasil. (2003). Lei de diretrizes e bases da educação nacional. Senado Federal, Subsecretaria de Edições Técnicas.

Brasil. (2011). Portaria normativa $n^{o} 40$, de 12 de dezembro de 2007. http://download.inep.gov.br/educacao_superior/censo _superior/legislacao/2007/portaria_40_12122007.pdf.

Brzezinski, I. (2002). Profissão Professor: Identidade e profissionalização docente. Plano Editora.

Fonseca, C. V., \& Santos, F. M. T. (2015). O Perfil de Cursos de Licenciatura e Estudantes de Química do Brasil: Contribuições do ENADE/2011. In: Encontro Nacional de Pesquisa em Educação em Ciências, 10., 2015, Águas de Lindóia. Anais eletrônicos... Águas de Lindóia: ABRAPEC. http://www.abrapecnet.org.br/enpec/X-enpec/anais2015/resumos/R0352-1PDF.

Griboski, C. M. (2012). O ENADE como indutor da qualidade da educação superior. Estudos em avaliação educacional, 23(53), $178-195$.

INEP/DAES. (2016). ENADE 2015. Exame Nacional de Desempenho dos Estudantes. Relatório de IES. Universidade Federal do Espírito Santo - São Mateus. Brasília.

INEP/DAES. (2018). ENADE 2017. Exame Nacional de Desempenho dos Estudantes. Relatório de IES. Universidade Federal do Paraíba. Brasília.

Knechtel, M. R. (2014). Metodologia da pesquisa em educação: uma abordagem teórico-prática dialogada. Intersaberes.

Lehfeld, N. A. S., Caritá, E. C., Gabarra, M. H. C., \& Miranda, C. E. S. (2016) Avaliação do comportamento de alunos no Exame Nacional de Desempenho de Estudantes (ENADE) por uma Comissão Própria de Avaliação. In: Simpósio Avaliação da Educação Superior, 2, 2016, Anais eletrônicos... Porto Alegre: UFRGS. http://www.ufrgs.br/avalies2016/anais-do-evento/artigos-1/156867.pdf/view.

Mello, J. A. V. B., \& Sousa, F. R. (2015). Caminhos formacionais na engenharia de produção: a formação docente e os resultados do ENADE 2011. Revista Gestão Universitária na América Latina-GUAL, 8(2), 199-215.

Merlo, T. (2018). A percepção dos estudantes sobre a formação na universidade: uma análise por meio do questionário do estudante do ENADE. (2018). Dissertação (Mestrado Profissional em Gestão Pública) - Universidade Federal do Espírito Santo, São Mateus.

Miranda C. L., Rezende, D. B., \& Lisbôa, J. C. F. (2015). A Licenciatura e a construção das representações sociais sobre ser professor de química. Investigações em Ensino de Ciências, 20(2), 01-11.

Oliveira, S. M. (2014). Impacto do perfil dos professores na nota do ENADE: Uma análise dos cursos de ciências contábeis nas universidades federais brasileiras. Trabalho de Conclusão de Curso (Bacharelado em Ciências Contábeis) - Universidade Federal de Goiás, Goiânia.

Pereira, A. S., Shitsuka, D. M., Parreira, F. J., \& Shitsuka, R. (2018). Metodologia da pesquisa científica. UFSM. https://repositorio.ufsm.br/bitstream/ handle/1/15824/Lic_Computacao_Metodologia-Pesquisa-Cientifica.pdf?sequence=1.

Pimenta, S. G., \& Anastasiou, L. (2002). Docência no Ensino Superior. Cortez Editora.

Prodanov, C. C. \& Freitas, E. C. (2013). Metodologia do trabalho científico: métodos e técnicas da pesquisa e do trabalho acadêmico. Novo Hamburgo: Feevale.

Ramalho, B. L. (2006) Reflexões sobre o ensino e o exercício da docência no ensino superior. Coleção Pedagógica, (1), 26 -32.

Soares, S. R., \& Cunha, M. I. (2017) Qualidade do ensino de graduação: concepções de docentes pesquisadores. Revista da Avaliação da Educação Superior, $22(2), 316-331$

Torres, A. R., \& Almeida, M. I. (2013) Formação de professores e suas relações com a pedagogia para a educação superior. Revista Brasileira de pesquisa sobre formação docente, 5(9), 11-22.

Yin, R. K. (2015). O Estudo de caso. Bookman. 